\title{
FEMINISMO Y FEMINISMOS: CONSENSOS Y DISENSOS ${ }^{1}$
}

\author{
Feminism and Feminisms: Consensuses and Dissensuses
}

Feminismos e feminismos: consensos e dissensos

\author{
JUANITA BARRETO GAMA \\ Universidad Nacional de Colombia \\ juanitamariabaga@yahoo.com
}

Ante todo quiero saludar a presentes y ausentes y dedicar estas palabras a todas las mujeres muertas por su condición de mujeres en su casa o en la plaza, a quienes han sido desplazadas por el conflicto armado en Colombia y a quienes nos dejaron su legado en la práctica cotidiana de las éticas del cuidado, caminando en la búsqueda de respuestas a la pregunta: «¿Qué sentido tiene la revolución si no podemos bailar?».2

Quiero también invitar a que nos miremos dentro y nos preguntemos acerca de los caminos andados por cada una de las aquí presentes para descubrir en ellos los materiales que hemos ido acuñando en nuestras historias para cambiar tres metáforas:

1. la metáfora de la cuadratura del círculo animada por los círculos concéntricos que cierran los caminos;

2. la metáfora de los triángulos de poder, con su correlato en los triángulos que nos simbolizan los debates entre y sobre las relaciones entre el poder del amor, el poder del saber y el poder del poder;

3. la metáfora de la sociedad armónica y de las mujeres bellas que han convertido y mantenido a las mujeres como objetos de consumo, y al consumismo como modelo homogenizante y única opción universal para el desarrollo de la economía, la política y la cultura y la sociedad.

Hoy pienso que la deconstrucción de estas metáforas nos va llevando a construir una nueva metáfora, una que parte de aquella que animara Virginia Woolf en $U n$ cuarto propio y la proyecta en búsqueda de conexiones:

La metáfora de la casa, esa casa que es nuestro cuerpo siempre ligado y situado en los territorios que habitamos y en los territorios que llevamos dentro; esa casa que es también nuestro cuarto propio y que está en posibilidad de conectarse con los cuartos propios que construimos en la acción colectiva de las mujeres.

\footnotetext{
${ }^{1}$ Encuentro Nacional de mujeres feministas de Colombia, Bucaramanga, octubre 25 de 2010.

${ }^{2}$ Una invitación a consultar la bibliografía y a dialogar con las autoras y los autores que han animado estas reflexiones y que hoy comparto al citar las fuentes vivenciales y las fuentes bibliográficas que se hicieron presentes en mis recuerdos al construir esta intervención.
} 


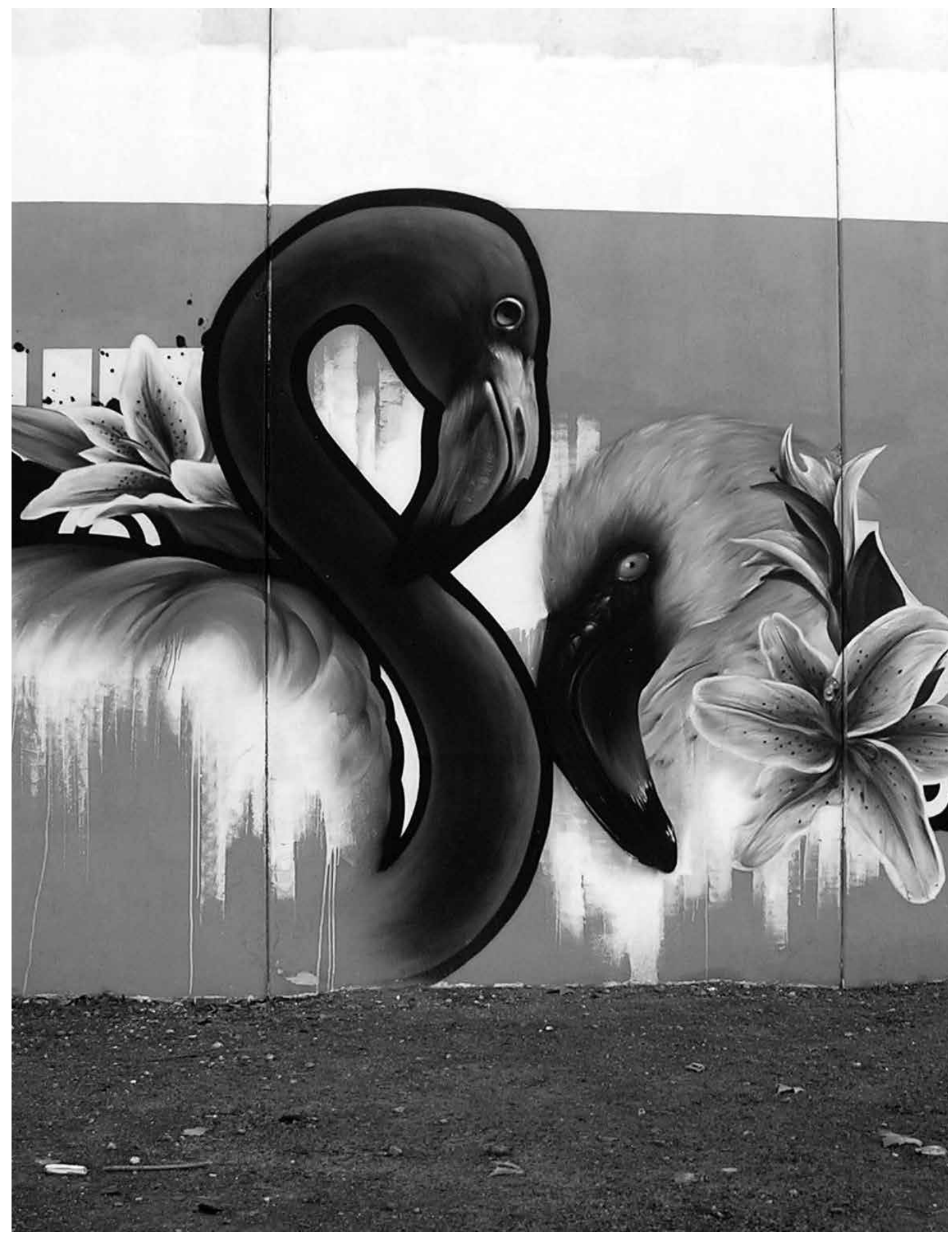

Detalle. Grafiti en el Paseo Rey Juan Carlos I en Sevilla - 2008 martin_javier - https://www.flickr.com/photos/31095500@N02/ 
Una casa en cuyos cimientos están las voces y apuestas de las mujeres que nos antecedieron en los milenios de la historia de la cultura patriarcal.

Una casa que en sus techos da cuenta de los límites y al mismo tiempo a través de sus puertas y ventanas que se abren y se cierran al ritmo con el cual cada mujer construye su autonomía, nos conecta con el infinito que tiene el tamaño de nuestros sueños.

Una casa en cuyas paredes están las mujeres, grupos y organizaciones de mujeres con quienes hemos departido en nuestras trayectorias personales $y$, también, las autoras y escritoras a quienes nos hemos acercado a través de sus escritos y de las obras vivenciales y monumentales que nos han legado en sus incesantes procesos de reproducción y transformación de la cultura patriarcal.

Ahora debo decirles a ustedes que no ha sido sencillo para mí preparar estos veinte minutos de participación en este panel, porque el tema central que nos fue dado, Feminismos en Colombia: realidades y utopias, es tan amplio como las preguntas por la génesis, el devenir y el porvenir del feminismo, de los feminismos y de los sueños que lo han animado. También porque a medida que ha pasado el tiempo, ese tiempo en el cual siempre están fundidos el tiempo de la historia de la humanidad y del país con el tiempo de mi propia historia y con el tiempo de mis antecesores y sucesores, de mis antecesoras y sucesoras, mis relaciones con el feminismo, y más recientemente con los feminismos, han sido muchas, intensas, variadas, contradictorias $\mathrm{y}$, ante todo, plenas de posibilidades.

Opté por concentrar mi atención en la pregunta por el paso del feminismo a los feminismos, centrando la mirada en el problema de los consensos y los disensos siempre presentes en los procesos que lo han animado, los cuales también en su amplitud y su complejidad me permiten hoy, para hacer más sencilla esta tarea, proponer cuatro preguntas, a modo de punto de partida, y aventurarme en el camino de tejer posibles respuestas; un tejido que ya ha sido construido y que cuenta hoy con mantas, colchas, telas e hilos de diversos calibres, colores y olores que acogen infinidad de sabores y saberes.

Son estas las cuatro preguntas:

1. ¿Cuál es en la actualidad la relación entre el feminismo y los feminismos?

2. Y en esa relación, ¿qué lugar han tenido y tienen hoy los consensos y los disensos? y ¿son éstos necesarios, deseables, posibles?

3. ¿Es el consenso una feliz, hermosa y paradisíaca utopía y el disenso una dramática, dolorosa e infernal realidad?

4. ¿Las experiencias que hoy mantienen vivo el feminismo, en sus diferentes dimensiones, matices, vertientes, corrientes y conceptos que ya se nombran 
como feminismos, ciberfeminismos y transfeminismos permiten proponer el disenso como utopía que alimenta la vida, ante la desolación de los territorios producto de la pretensión inhumana del consenso?

No pretendo responder estas preguntas, solamente echarlas a andar o mejor hacerlas visibles para que puedan encontrarse con otras muchas y más precisas preguntas que acompañan tanto a mis compañeras de mesa como a todas y cada una de quienes hicieron un alto en el camino para concurrir a este escenario.

Debo decirles en este momento que quisiera, por razones de tiempo, utilizar los minutos que me quedan, no para aventurar mis posibles respuestas a estas cuatro preguntas, sino para poner en escena el texto de una canción que acompañó a muchas de quienes estamos hoy acá. Una canción que lleva por título precisamente Cuatro preguntas, ${ }^{3}$ una canción que nos cuenta, tal vez sin darnos cuenta, la

3 Cuatro preguntas Autor: Eduardo López Compositor: Pedro Morales Pino Interpretada por: Los Músicos. Ritmo: Bambuco Instrumentos: tiple y bandola. Letra: Niegas con él lo que hiciste y mi sospecha te asombra/pero, si no lo quisiste ipor qué te pones tan triste/cuando en tu casa le nombran? //

Dices que son cosas mías y que me estoy engañando,/ mas,/ipor qué le sonreías, sonreías cuando él te estaba mirando?// Si aún en no ser te empeñas, culpable como pareces,/ si él te odia y tú le desdeñas/ ipor qué, por qué tantas veces os vi entenderos por señas?// Si no te dejaste en derroche de amor que te acariciara/ipor qué te azotó una noche,/ una noche con el pañuelo en la cara? profundidad, la persistencia del patriarcado que se resiste a desaparecer. Una canción que con seguridad ha sido objeto de análisis, de estudio, de trabajo en sesiones realizadas con y entre mujeres, para interrogar las violencias contra las mujeres, las violencias o las violencias basadas en el género; para preguntarnos sobre las expresiones o tipos de violencia ¿sutilmente? presentes en esta canción; para saber por qué en algunos momentos al entonarla respondemos que no es necesario exagerar y la cantamos con la añoranza de un recuerdo del que no sabemos bien si nos hace daño o no; por lo pronto, para descubrir la sutileza de una letra $s$, así con minúscula cuando pasamos de lo que no hace daño a lo que nos hace daño.

Nací en plena mitad del siglo XX y puedo decir que desde la primera década de mi existencia, aun sin saberlo, y de pronto sin que muchos quisieran que algún día lo supiera — lo supiéramos—, el feminismo debió entrar por mis poros e inscribirse suavemente en mis entrañas. El feminismo, así en singular, entró a mi ser silenciosamente, en medio del dolor y la alegría, en plena confrontación y coexistencia de la vida y la muerte. La violencia de los ańos cincuenta y de los desplazamientos de quienes huían de la muerte que asolaba los campos fue el contexto en el cual las mujeres que clamaban por el reconocimiento de su condición de ciudadanas celebraban en 1954 el derecho al voto y lo ejercían participando activamente en el plebiscito de 1957. No supe si mi madre, mis abuelas o mis tías sabían del feminismo cuando cambiaron sus tarjetas de identidad que las signaba o señalaba como tuteladas en el cincuenta y cuatro o cuando concurrieron por vez primera a las urnas en el cincuenta y siete, llevando en sus manos un documento 
que las acreditaba como ciudadanas. Tampoco sé si mi padre, mis abuelos o mis parientes varones sabrían de la existencia del feminismo o de las sufragistas y qué pensaban de ellas y de las diferentes condiciones en que ellos y ellas ejercían la ciudadanía en ese momento.

Hoy comprendo que haber nacido en este territorio precisamente cuando el siglo XX se partía en dos me hace parte de las generaciones de mujeres que nacieron en Colombia sin tener inscrita en sus cuerpos la condición de ciudadanas, y también de las generaciones que inauguraron la ciudadanía de las mujeres, una conquista en el camino de la construcción de los valores del pensamiento moderno hasta ese momento considerada una utopía. Una conquista que está siendo interrogada por algunas corrientes del pensamiento postmoderno, cuando aún las utopías animadas por los valores de la libertad, la igualdad, la solidaridad y la justicia. Una conquista que aun yo misma no puedo poner en cuestión por cuanto considero que su realización es parte del proceso de poner en la escena de la historia las historias de las mujeres.

El feminismo se fue depositando en mi cuerpo durante las primeras tres décadas de mi existencia. De la década del sesenta sigo percibiendo el aroma de los vientos de cambio, de los movimientos contraculturales, de las luchas contra el coloniaje, contra el racismo, el sexismo y todas las formas de dominación, subordinación y discriminación. La fuerza transformadora del mayo del sesenta y ocho, la píldora y los métodos de planificación familiar con sus apuestas por la libertad de las mujeres para el amor y al mismo tiempo por el amor a la libertad transitaban por el mundo pretendiendo hacer frente a otras guerras, muchas guerras localizadas y que iban configurando un nuevo orden mundial como rescoldos de las dos guerras mundiales que ensangrentaron la primera mitad del siglo XX. Rescoldos que aún persisten y que me hacen evocar cuando esto escribo la canción colombiana Cenizas al viento, rescoldos que traen a mis memorias internas ya no el suave carraspeo de las cenizas, sino el ruido ensordecedor de las guerras y que por tanto, al mismo tiempo, me invitan a nombrar a Alessandra Bochetti especialmente en su discurso sobre la guerra y las mujeres, en sus deseos por construir a las mujeres como nuestras semejantes, y en sus denuncias del absurdo de pretender alcanzar el bienestar con la sangre y el sacrificio de las vidas de quienes lo proponen como condición para toda la humanidad. ${ }^{4}$

En el cruce de los años sesenta y setenta empecé a percibir las omnipresentes tensiones entre los intereses personales y los colectivos y a asumir opciones que

${ }^{4}$ Y permítanme acá decir desde ya gracias a Safo de Lesbos, a las mujeres troyanas, a Hipatia de Alejandría, a Artemisa, a Olympia de Gouges, a las mujeres de Milán y a todas las mujeres que alimentan discursos como los que leemos en la obra de Alessandra Bocchetti, todas las cuales están hoy nutriendo los encuentros entre el feminismo de antaño y los feminismos de hoy. me permitieron empezar a reconocer a las mujeres como mis semejantes, tal como lo fuera descubriendo a medida que avanzaba y se transformaba mi inserción en la vida universitaria inicialmente como discente, en $\mathrm{mi}$ encuentro con las cerca de treinta y 
cinco compañeras y dos compañeros de aula, en mis conversaciones y debates con el grupo de amigas universitarias — hoy los y las jóvenes llamarían «mi parche»—, y luego, a través de una experiencia docente que se mantiene.

El feminismo de los años setenta se ancló en mi cuerpo con palabras más fuertes; conocí el feminismo profundamente ligado a los idearios de una sociedad en la cual el valor de la igualdad se viviera como una condición para hacer frente a la concentración de la riqueza y a la carencia de soberanía de los pueblos. En esta década leí por primera vez a Simone de Beauvoir, de quien aprendí a formular muchas preguntas sobre Elsegundo sexo, y unos años después sobre Los mandarines, La sangre de los otros y La mujer rota, los cuales me permitieron acceder a la palabra feminista para interrogar todos los mandatos en los cuales se han cimentado y se sostienen aún las relaciones de dominación de las mujeres y su correlato en las relaciones de subordinación. ${ }^{5}$

En la década del setenta están también los debates frente a los procesos de planeación

${ }^{5}$ Acá mis recuerdos me obligan a nombrar a amigas como Martha Méndez, quien ha recorrido el mundo buscando diversas opciones de vida construidas por mujeres y con quien me acerqué a Simone de Beauvoir en esta década, y como Marisol Isaza quien en las aulas universitarias tuvo la osadía en esta década de nombrar el orgasmo clitorial y de hablar de las relaciones estrechas entre feminismo y ambientalismo advirtiéndonos sobre la existencia de este feminismo que empezó a nombrarse como ecofeminismo. del desarrollo inspirados en el influjo de la planificación estatal cuando los juegos, más de sombras que de luces, de la guerra fría situaban a los países en la confrontación de dos bloques de poder, en cuya conformación las utopías que animaban los valores de la libertad y de la igualdad pugnaban entre sí para sustentar otras múltiples contiendas.

La guerra entre la libertad y la igualdad ocultaba, hacía lejana y pisoteaba la utopía de la fraternidad y la solidaridad. El paradigma racionalista interrogaba, preguntaba, construía explicaciones en medio de una lenta y a la vez creciente legitimación del acceso de las mujeres a la educación y a un mundo laboral en el que la industrialización y los servicios demandaban la "mano de obra femenina», en el cual la vinculación de las mujeres al trabajo remunerado reproducía las condiciones de existencia subordinada de las mujeres.

Mi feminismo de los años setenta empezó también con las preguntas sobre el incesante trabajo de las mujeres en los barrios y veredas, en los pueblos y ciudades, donde fui aprendiendo que la participación comunitaria y la participación social eran ámbitos por excelencia de la vida cotidiana de las mujeres, y que el valor asignado a estas dimensiones de participación era significativamente inferior que el asignado a la participación política. Descubrí entonces que también estas relaciones se representan en el triángulo de poder en cuyo vértice superior está el poder político, del cual dependen o al cual se deben los micropoderes de la vida cotidiana representados en la participación social y la participación comunitaria. 
Incursioné en esta década en los encuentros y desencuentros entre los movimientos políticos, los que fueron llamándose viejos movimientos sociales, entre los cuales se encontraban los movimientos sindicales y los movimientos campesinos, y allí descubrí las profundas tensiones derivadas de las dobles militancias de quienes preguntaban a sus compañeros y compañeras de partido, de sindicato o de otras formas organizativas, ¿dónde o cómo van los derechos de las mujeres en la dinámica de estas formas asociativas?

Allí la pregunta por el trabajo comunitario de las mujeres se unió a las preguntas sobre el valor del trabajo doméstico y a las experiencias organizativas de las llamadas "empleadas de servicio", quienes empezaban a demandar reconocimiento a sus derechos laborales, también las de quienes se dedican al oficio de la prostitución y reclamaban los derechos correspondientes con su condición de «trabajadoras del sexo». Las demandas de las mujeres por un trabajo digno y por ingresos justos se alimentaron de los caminos andados por el movimiento feminista y por las diversas vertientes del pensamiento feminista y se entrecruzaron con las luchas por los derechos económicos, sociales, culturales y ambientales, y con las luchas de los derechos de los pueblos.

Las tensiones entre los intereses de clase y los intereses de las mujeres estaban presentes en muchos espacios, por no decir que en todos. Comenzaban a conformarse los departamentos, secciones o comisiones de mujeres en las diversas organizaciones sociales y los dilemas de las dobles o triples pertenencias acompañaban las dobles y triples jornadas de trabajo de las mujeres, y hoy siguen acompañando la que se nombra como «jornada redonda» para referirse al trabajo incesante de las mujeres. Un ejemplo de éste son los datos aún exiguos y poco difundidos sobre la prevalencia de las mujeres en los estudios nocturnos, y de manera específica en los programas nocturnos del SENA o en los cursos virtuales.

El Feminismo con $\underline{F}$ mayúscula fue echando raíces en mi cuerpo alimentado por las preguntas y alimentando otras preguntas más por las relaciones entre los viejos y los nuevos movimientos sociales, entre los cuales se empezaba a contar el «movimiento de mujeres», y dentro de éste el «movimiento feminista». Estas preguntas tenían diferentes maneras de ser formuladas cuando provenían del saber de las mujeres de sectores populares o de los saberes interrogados e interpelados por los debates acerca de las relaciones entre conocimiento común y conocimiento científico en el ámbito académico.

Mi feminismo de los ańos ochenta estuvo alimentado con los sabores de la denominada década internacional de la mujer y con la puesta en escena de los debates que permitieron pasar de las preguntas y propuestas acerca de la Mujer en el Desarrollo a las preguntas y propuestas sobre el Género en el Desarrollo. Y de manera muy especial, mi feminismo se nutrió de la existencia de las colegas y amigas que nacían como Grupo Mujer y Sociedad en el momento mismo en el 
cual ingresé a la planta docente de la Universidad Nacional de Colombia ${ }^{6}$, después de haber sido durante algunos semestres docente interina u ocasional en ella, y con el acumulado de haber compartido, en la década del setenta y los primeros años de la del ochenta, con mis colegas docentes y estudiantes del Colegio Mayor de Cundinamarca y del Externado de Colombia muchas preguntas acerca de las condiciones de la mujer y de las mujeres en el ámbito educativo.

En la Universidad Nacional de Colombia viví la profunda conexión entre la autonomía universitaria, que no había percibido de manera concreta en las otras universidades a las cuales había estado vinculada, y el ejercicio cotidiano de la autonomía personal. Por ello en las tres décadas en las cuales transcurrió mi inserción en la vida universitaria, tenía ante mis ojos el triángulo de poder conformado por el Estado, la Academia y la Sociedad Civil. Un triángulo en el cual las disputas entre estas «esferas» respecto al vértice superior, expresión del máximo poder, se hicieron más fuertes.

Si en las primeras décadas mi existencia estuvo signada por el sacrosanto triángulo del poder patriarcal representado en la familia patriarcal en cuyo vértice superior estaba el varón como cabeza de familia, y en la tercera década mi cuerpo experimentó los avatares del triángulo que sitúa en el vértice superior al poder politico que subordina los poderes sociales y los comunitarios, en mi cuarta década, es decir, en mi tránsito de los treinta a los cuarenta, estuve signada por las preguntas relativas a las tensiones emanadas de las relaciones entre estado, academia y sociedad civil.

Preguntas, debates y combates entre estos tres actores para definir quién o cuál de ellos estaba en el vértice, construidas en medio de la reproducción de las jerarquías y de otros triángulos de poder que sustentan los triángulos más grandes, tales como el

${ }^{6}$ Entre finales del año 1985 y comienzos de 1986 Florence Thomas, María Eugenia Martínez, María Himelda Ramírez y Guiomar Dueñas, habían comenzado a reunirse, a buscar un nombre para identificarse-inicialmente pensaron en Lilith-y luego decidieron un nombre que tuviera una connotación mas audible en el mundo universitario: «mujer y sociedad». Muy pronto se unió a ellas Yolanda Puyana. Recuerdo de manera especial el Simposio sobre vida cotidiana organizado por Florence Thomas, en ese entonces directora del Departamento de Psicología realizado en Bogotá entre el 27 y el 31 de enero 1986, cuyas ponencias fueron publicadas por el ICFES en la "Serie memorias de eventos científicos colombianos». Ubico con detalle este evento porque en mi recuerdo quedó registrado como un escenario al cual concurrieron las profesoras integrantes del naciente grupo con sus ponencias síntesis de investigaciones que realizaban en ese momento. Si bien fui invitada a participar en las reuniones del grupo desde sus inicios, tardé un tiempo en decidirme a participar activa y formalmente en él. No sobra tener presente que todos los grupos tienen rituales de iniciación y éste no era la excepción. Tampoco sobra decir que acceder a formar parte de un equipo de trabajo, de un grupo o de una expresión concreta de un movimiento social es un arte muy semejante al de la seducción y tan complejo como éste, pues requiere atracciones mutuas. Hoy, deseo decir a gracias a estas amigas y colegas fundadoras antes nombradas, gracias por haber gestado este grupo. También a quienes fueron formando parte de él y continúan siendo integrantes activas hoy: a Dora Isabel Díaz, hoy presente en este auditorio; a Circe Sencial, Patricia Prieto, Noema Hernández y María Mercedes Tello, con quienes seguimos siendo partícipes de las sesiones habituales de este grupo en la actualidad, tal vez aprendiendo más de los disensos que de los consensos frente a las inseparables relaciones entre el feminismo, los feminismos y las feministas que los reinventan día a día. Reconocer hoy también los feminismos encarnados en Magdalena León, Anita Rico, Donny Meertens, María Cristina Salazar, Martha López, Ángela María Estrada, Luis Santos, Patricia Jaramillo, María Elvia Domínguez, Ángela Inés Robledo, Lya Yaneth Fuentes, Elsa Olid Rondón, Zully Moreno, Gloria Elena González y Angélica Bernal, quienes vivieron su pertenencia al grupo durante algunos años y con quienes aprendimos el respeto que nos merece y nos preserva el ejercicio de la autonomía. A profesoras visitantes, como Arline Prigoff, y a estudiantes que pasaron por algunos semestres por la Universidad y establecieron relaciones de intercambio con este grupo, animando con su presencia las sesiones de algunos periodos. 
triángulo de poder entre naciones del primer, segundo y tercer mundos, o entre los supraestados, los estados nacionales y los estados-nación no viables, o el no menos explícito triángulo de poder entre las ciencias, las disciplinas y las profesiones, o entre las ciencias duras, las ciencias blandas y las artes y prácticas que se resistían a ubicarse entre la dureza de las ciencias de la naturaleza y la blandura de las ciencias del espíritu, o los diversos triángulos de poder que podríamos simbolizar entre las diversas formas de organización de la sociedad civil, sobre cuya existencia muchos y muchas dudaban y dudan aún; baste mencionar, a manera de ejemplo, uno de los muchos triángulos que acá podríamos dibujar: los gremios y sociedades de diverso tipo, las organizaciones sociales y las organizaciones no gubernamentales.

Allí con el Grupo mujer y sociedad, debatimos acerca de las relaciones entre la academia y los movimientos sociales, entre el feminismo académico y las nacientes redes, grupos y organizaciones de mujeres; participamos activamente de los procesos de Reforma Constitucional en la Colombia que se dibujaba con nuevos contornos al dar lugar en la Carta Magna del 91 a nombrar la participación como un derecho y como un deber, a registrar los derechos humanos como uno de sus capítulos, a declarar a Colombia como un Estado Social de derecho, de carácter laico y pluricultural, un país de regiones en las cuales también circulan la diversidad y la diferencia, una Colombia clasista, elitista y discriminadora que aún difícilmente abría camino a reconocer las comunidades negras y afrodescendientes y los pueblos indígenas. Una Constitución que al mismo tiempo incluyó el artículo 43 relativo a la autonomía de las mujeres y el artículo 42 relativo a la familia patriarcal, en el cual aún se aprecian componentes que mantienen la simbiosis mujer y familia, con la cual, al mismo tiempo que se enuncian los principios de igualdad y respeto a las diferencias se incluyen expresiones que legitiman el sacrificio de los derechos de las mujeres en defensa de la sacrosanta familia patriarcal. ${ }^{7}$

${ }^{7}$ Artículo 42. La familia es el núcleo fundamental de la sociedad. Se constituye por vínculos naturales o jurídicos, por la decisión libre de un hombre y una mujer de contraer matrimonio o por la voluntad responsable de conformarla. El Estado y la sociedad garantizan la protección integral de la familia. La ley podrá determinar el patrimonio familiar inalienable e inembargable. La honra, la dignidad y la intimidad de la familia son inviolables. Las relaciones familiares se basan en la igualdad de derechos y deberes de la pareja y en el respeto recíproco entre todos sus integrantes. Cualquier forma de violencia en la familia se considera destructiva de su armonía y unidad, y será sancionada conforme a la ley. Los hijos habidos en el matrimonio o fuera de él, adoptados o procreados naturalmente o con asistencia científica, tienen iguales derechos y deberes. La ley reglamentará la progenitura responsable. La pareja tiene derecho a decidir libre y responsablemente el número de sus hijos, y deberá sostenerlos y educarlos mientras sean menores o impedidos. Las formas del matrimonio, la edad y la capacidad para contraerlo, los deberes y derechos de los cónyuges, su separación y la disolución del vínculo, se rigen por la ley civil. Los matrimonios religiosos tendrán efectos civiles en los términos que establezca la ley. Los efectos civiles de todo matrimonio cesarán por divorcio con arreglo a la ley civil. También tendrán efectos civiles las sentencias de nulidad de los matrimonios religiosos dictadas por las autoridades de la respectiva religión, en los términos que establezca la ley. La ley determinará lo relativo al estado civil de las personas y los consiguientes derechos y deberes. Artículo 43. La mujer y el hombre tienen iguales derechos y oportunidades. La mujer no podrá ser sometida a ninguna clase de discriminación. Durante el embarazo y después del parto gozará de especial asistencia y protección del Estado, y recibirá de este subsidio alimentario si entonces estuviere desempleada o desamparada. El Estado apoyará de manera especial a la mujer cabeza de familia. (República de Colombia, 1991). 
Múltiples interrogantes acerca de las relaciones entro lo público y lo privado, lo personal y lo político, lo natural y lo cultural, lo individual y lo colectivo, el erotismo femenino y la sexualidad masculina, lo identitario y lo subjetivo, ante los cuales las feministas que nos antecedieron habían recorrido ya algunos trechos y habían abierto diversos caminos, animaron la edición del primer libro del Grupo mujer y sociedad: Mujer, amor y violencia. Nuevas interpretaciones de antiguas realidades, la inserción en los debates sobre el género como categoría analítica y los aún vigentes debates acerca de los encuentros y desencuentros entre los estudios de y sobre la mujer, los estudios de género, los estudios feministas, los más recientes estudios queer, los estudios sobre nuevas masculinidades y nuevas identidades sexuadas y corporizadas, alimentaron el vertiginoso e intenso paso de la cuarta a la quinta década de mi existencia.

Estas y muchas otras preguntas me permitieron sentir con las mujeres otras dimensiones de la posibilidad de cuidar y mantener la vida ante el dolor que nos acompañó durante estas décadas en las cuales hemos visto caer en el fragor de las guerras y los desplazamientos forzados a tantos compañeros y compañeras de la cultura, la política y la acción social, décadas en las cuales hemos visto circular la reproducción ampliada de las violencias sobre los cuerpos de mujeres y hombres que pareciera no tener fin. Violencias en las cuales los cuerpos de las mujeres han sido y siguen siendo botín de guerra, y los cuerpos de los varones eliminados del territorio y consagrados por las sacrosantas instituciones como héroes o villanos. Violencias con mayúsculas que se sustentan en las violencias aparentemente minúsculas y que sostienen un conflicto armado ante el cual ese triángulo de poder: Estado-Academia-Sociedad Civil no logra, en medio de sus disputas, escuchar realmente las voces de quienes proponen y promueven la solución humanitaria del conflicto armado. Paradójicamente pensé en cambiar las expresiones proponen y promueven por claman, como clamaban las multitudes ante su rey en épocas que parecieran remotas, pero solo lo dejo registrado acá ante mi convicción de que existen diferencias sustanciales entre las monarquías y las repúblicas, aun si las sedes de los gobiernos republicanos persisten en llamarse palacios. Son diferencias que le han dado giros a la historia eterna de opresión y subordinación, de emancipación y construcción de la autonomía.

Fue así como ya no de manera imperceptible, en el curso de mi quinta década que ya se extingue y que da paso a la sexta de mi existencia, con el Grupo mujer y sociedad fuimos haciendo consciente y creciente su descendencia que podríamos llamar sus hijos y sus hijas, entre los que se cuentan:

1. Un hijo prematuro llamado Fondo de Documentación Mujer y Géneros, ${ }^{8}$ nacido en el año 1993.

${ }^{8}$ Y acá, un explícito reconocimiento explícito a Magdalena León, quien como parte de su historia feminista gestó la Biblioteca Ofelia Uribe de Acosta que dotó con sus publicaciones y con buena parte de su biblioteca personal, la cual funcionó durante sus primeros años en Bogotá, en la Cra. 25 entre calles 39 y 39 A del barrio La Soledad, y que decidiera donar a la Universidad Nacional de Colombia cuando formaba parte del Grupo Mujer y Sociedad, y como antesala del nacimiento del Programa de Estudios de Género del cual entró a formar parte en el momento de su nacimiento como Fondo de Documentación Mujer y Género. 
2. Un hijo un tanto ilegítimo llamado Programa de Estudios de Género, Mujer y Desarrollo que entre los años 1994 a 2001 buscaba un lugar en el lentísimo proceso de institucionalización. ${ }^{9}$ Este hijo se ubicó al nacer en la Unidad Camilo Torres, a la cual por esa misma época se trasladó el Centro de Estudios Sociales —CES— de la Facultad de Ciencias Humanas.

3. Dos hijas nacidas con la posibilidad de conferir títulos y nacidas del matrimonio entre el Programa de Estudios de Género y el Departamento de Trabajo Social, el cual dio nacimiento y albergue institucional a las primeras generaciones de Especialistas en Proyectos de Desarrollo con Enfoque de Género y de Maestría en Estudios de Género.

4. Una hija gozosa y libertaria, la revista En Otras Palabras... cuyo número 1 vio la luz en 1996, producto de las alianzas entre el Grupo Mujer y Sociedad, la Corporación Casa de la Mujer de Bogotá, la Fundación Promujer y el Programa de Estudios de Género, alianzas que fueron variando durante sus diez números de existencia y que hoy, próxima a la edición número 18 , se resiste a la indexación y a los dictámenes de Colciencias.

5. Una última hija, nacida en los albores del siglo XXI (2001), bautizada institucionalmente con el nombre de Escuela de Estudios de Género, al mismo tiempo en que naciera la Escuela de Estudios de Psicoanálisis y Cultura. Cabe señalar una pequeña diferencia entre estas dos escuelas: la de psicoanálisis y cultura desde el momento en el cual nació cuenta con seis docentes de planta, mientras que la de estudios de género, después de diez ańos de existencia solo tiene una docente de planta y el 75\% del tiempo de otra docente. No sobra precisar en este recuerdo, la riqueza de las discusiones, los intercambios, los encuentros, los desencuentros entre quienes integraron el Grupo interdisciplinario de psicoanálisis y quienes integramos el Grupo interdisciplinario mujer y sociedad, así como las amplias posibilidades que se gestaron en el devenir de estos dos grupos. ${ }^{10}$

\footnotetext{
${ }^{9}$ Y lo llamo un tanto ilegítimo porque no tenía lugar en la estructura institucional, y sin embargo creó su lugar en el territorio de la ciudad universitaria donde en las décadas anteriores estuvieron ubicadas las antiguas residencias Gorgona, para estudiantes procedentes de otras regiones del país- hoy llamado Unidad Camilo Torres, lugar que comparte con el Centro de estudios Sociales -CES-, en el bloque 5-6, justo a la sombra de la rectoría de la UN.

${ }^{10}$ Acá cabe señalar como una fuente imprescindible de consulta para mantener los debates acerca de las relaciones entre feministas y psicoanalistas, entre feminismo y psicoanálisis, la obra de Luis Santos Velásquez, quien durante más de una década formó parte del grupo Mujer y Sociedad.
}

Es en este ámbito de la academia que siempre se nutre y a la vez nutre a las demandas de los movimientos sociales, y de las incesantes, viejas y nuevas preguntas acerca de las relaciones entre la ciencia, la tecnología y la política, e interrogantes sobre si es posible, deseable o necesario pensar la universidad y la democracia como una preocupación del orden teórico o como una relación vivida y puesta en 
práctica dentro y fuera de la universidad, que se hicieron presentes las preguntas sobre las relaciones entre las dimensiones políticas, epistemológicas, subjetivas e identitarias del feminismo. ${ }^{11}$ Las especificidades de cada una de estas dimensiones y sus profundas articulaciones, como también sus variadas y profundas rupturas, estuvieron presentes en la gestación y el desarrollo de los feminismos de la igualdad y de la diferencia, liberal, socialista y radical, del «feminismo negro» o black feminism, con el cual develábamos los profundos nexos entre sexismo, racismo y clasismo y la construcción de caminos para encontrarnos en las luchas contra los procesos de opresión; así mismo, nos reconocimos en las diversas corrientes del eco-feminismo anteriormente enunciado, y fueron emergiendo no sin dificultad los encuentros con otros feminismos: con los feminismos cibernéticos que nos asombran y nos asustan, nos iluminan y nos enceguecen con las luces deslumbrantes del ciberespacio. También con los más recientes feminismos lésbicos y con los transfeminismos que ofrecen nuevas posibilidades para controvertir, develar y denunciar la homofobia y el heterosexismo como modelo universal sustento y asiento del orden patriarcal ${ }^{12}$.

Es en los difíciles debates acerca de las relaciones entre academia y política, entre una academia que se proclama neutra y aséptica y una academia que reconoce su responsabilidad social, ética y política, que a mediados de la década que está terminando este año, la vida - a instancias de mujeres, grupos, redes y organizaciones de mujeres de Bogotá- me regaló una experiencia que merece un capítulo aparte y de la cual opté por no hablar en este panel. Solo diré que esta experiencia dio forma al que nombramos como "proceso de construcción colectiva de la política pública de mujer y géneros de Bogotá DC». ${ }^{13}$ Con esta experiencia, me sitúo en la última década de este recorrido para nombrar dos momentos diferentes y estrechamente conectados que entran en escena: el primero, desde mi inserción en instancias decisorias del gobierno distrital que cubre los ańos 20042007 como integrante del gabinete distrital del Alcalde Luis Eduardo Garzón,

\footnotetext{
${ }^{11}$ Es amplia la bibliografía ilustrativa de estas dimensiones. Registro en la bibliografía dos artículos en los cuales he aventurado algunas reflexiones sobre ellas.

${ }^{12}$ Luces de las cuales siempre emanan sombras, como aprendí cuando leí al Bachelard de los años setenta, quien afirmaba: «El conocimiento es una luz que siempre proyecta algunas sombras», un enunciado que fui comprendiendo en su profundidad a medida que encontraba epistemólogas feministas que interrogaban las sombras de la sempiterna razón patriarcal.

${ }^{13}$ Un reconocimiento especial a todas las mujeres que formaron parte del equipo que animó, puso en marcha y desarrolló este proceso, que ha quedado inscrito en nuestros cuerpos y anda con nosotras por donde transitamos y con quienes fuimos creciendo, multiplicando los equipos de trabajo en el Distrito Capital y descubriendo cómo de manera gradual y también a veces imperceptible el feminismo y los feminismos fueron incorporándose de manera diversa en sus cuerpos, en consonancia con sus experiencias y trayectorias vitales, con sus relaciones con los movimientos de mujeres y con otros movimientos sociales. Hoy digo gracias y renuevo acá mis especiales reconocimientos a Marta Buriticá, Patricia Prieto, Magdalena Barón, Elizabeth Quiñones, Sandra Mojica, Luz Yanira Garzón, Angélica Bernal, Alejandra Ortiz, Diana Marcela Gómez Correal, Chila Pineda, Martha Lucía Sánchez y con ellas a todas las mujeres que formaron y forman hoy parte de este proceso sobre el cual escribí, entre otros, un artículo en la revista En Otras Palabras (Barreto, 2009).
} 
como asesora del despacho y responsable de la que fue llamándose Oficina de Mujer y Géneros, una oficina sin lugar específico en la estructura institucional que fue creando su lugar en el territorio del distrito capital, y el segundo, desde mi inserción en instancias organizativas de la sociedad civil en el nivel distrital, que cubre los años 2008-2011, periodo durante el cual fui elegida para integrar el Consejo Consultivo de Mujeres de Bogotá. ${ }^{14}$

De esta manera hemos recorrido seis décadas en las cuales confluyen mi historia,

${ }^{14}$ Para conocer la génesis, composición, principios, objetivos y funciones del Consejo Consultivo de Mujeres del D.C. de Bogotá, puede consultarse el decreto 403 del 5 de septiembre de 2007 del Alcalde mayor de Bogotá y las demás normas que lo sustentan. nuestra historia y la historia del país en que vivimos y en el que hoy nos encontramos, de las cuales las tres últimas vieron la emergencia de los feminismos, llamados así, en un plural muy suave casi imperceptible, que como alcancé a enunciar antes, empezó a tomar forma en mi cuarta década, la de los ochenta y fue creciendo y consolidándose con fuerza en la de los noventa, cuando el nacimiento de una Colombia Constituyente que redefinía sus principios para ampliar la democracia alimentaba aún las ilusiones por un mundo en el que todos y todas cupiésemos. Una época en la cual la letra $S$, empezó a formar parte de los nuevos léxicos, en los cuales también me siento y me pienso inmersa, ya no para eliminar las palabras singulares y universales que las precedieron, sino más bien para dar lugar a la asignación de valores éticos a las diferencias, a todas las diferencias constitutivas de lo humano.

Una $S$ que muy recientemente recorre muchos rincones del mundo y muchas expresiones de la humanidad entera animando quienes la conforman a reconocer la diversidad, a asumir las diferencias con sentido ético-político y epistémico, a dar cuenta de la pluralidad, a asumir la coexistencia de lo uno y lo múltiple, a dar lugar al nacimiento del sí misma, de nosotras mismas como sujetas deseantes y no como objetos del deseo, de nosotras mismas como sujetas de derecho y no como sujetas al derecho patriarcal.

Una $S$ que nos habla de las profundas relaciones entre la violencia y las violencias, esas violencias cotidianas contra las mujeres por el hecho de ser mujeres en las que se sustentan todas las violencias estructurales que se siguen legitimando en las guerras.

Una y muchas $S$ que nos situaron en los pretendidos y falsos límites entre la modernidad y la posmodernidad. Esas $S$ que en el decir cotidiano nos hacen agua la boca, que animan la mirada de la sospecha, la complicidad, la pre-ocupación y la pregunta por si estamos en el fin de la historia o más bien en el incesante comienzo de nuevas historias que no tienen fin.

Esta historia que a Marcela Lagarde, situada en el dilema mismo de los universales, le permite afirmar a voz en cuello que «el feminismo es universal por primera vez en la historia». Esta historia sobre la que aprendí a preguntarme con Lucía Guerra 
acerca del sujeto femenino y la sujeta mujer cuando interrogaba por qué razones, precisamente en el momento en que emergen en la historia nuevos sujetos, los sujetos inesperados de Jean Lyotard, otras voces claman o proclaman a los cuatro vientos la eclosión del sujeto y el derrumbe de los universales.

Por ello esas cuatro preguntas que formulé al comienzo de mi intervención no son mías, quedan abiertas al debate público y por tanto al debate de cada una de las aquí presentes y de los colectivos a los cuales pertenecen, como también quedan de nuevo en sus mentes las cuatro preguntas de esta canción del folclor colombiano que sigue entonándose en nuestro territorio.

Y todas quedan acá registradas no para creer en ellas, sino para de-construirlas por medio de sus propias experiencias, de la acción individual y colectiva que nos acompaña al venir a este encuentro, con el deseo de que sean motivo para animar éste y muchos encuentros más. Para que se formulen de otras múltiples y variadas maneras y permitan la emergencia de nuevas y variadas historias. Para que nos permitan mantener vivo el deseo de contarnos los cuentos que necesitamos para conferir sentido a nuestra existencia. Para que contribuyan a volver al pasado, ya no para repetirlo, sino para conocerlo y desentrañar en él la siempre presente relación entre lo que se mantiene y lo que se trasforma. Para desatar nudos y reanudar el futuro contando con las apuestas y las propuestas del feminismo y de los feminismos en sus múltiples expresiones.

Para que quienes no son feministas comprendan que ni las feministas ni el feminismo deseamos la univocidad no solo porque no es deseable sino además porque no es posible, ni necesaria. No queremos un mundo en el que todos y todas sean feministas, deseamos un mundo en el cual todas y todos sepamos que gracias al feminismo estamos hoy en posibilidad de transitar espacios que nos habían sido vedados.

Queremos una Colombia en la cual sea posible descubrir el potencial transformador de esa magia que hoy nos permite reconocernos en las diferencias que nos constituyen y cuyas artes aprendimos en el feminismo que permitió la emergencia de la mujer como sujeta de la historia, sujeta de derechos y sujeta deseante, y que paulatinamente va abriendo sus puertas a la diversidad de feminismos, a su multiplicidad.

Y permítanme ustedes finalizar esta intervención escuchando algunas voces que han alimentado y hecho crecer mis diversos encuentros con el feminismo entre las certezas y las incertidumbres de la frágil condición humana, y diciendo gracias a todas y cada una de ellas:

Gracias a todas las mujeres anónimas que me enseñaron a decir una y muchas herejías, entre las cuales se destacan: 
Dios es negra.

Patriarca, tus pesadillas son nuestros sueños.

(Grafitis anónimos)

Gracias a todas las mujeres con quienes la vida nos permitió encontrarnos para aprender el valor de otras voces:

Nunca fui capaz de saber con precisión qué era el feminismo. Lo unico que sé es que la gente me llama feminista cada vez que expreso sentimientos que me diferencian de un limpión o un trapo» Traducción libre de un pensamiento de Rebecca West, hoy dia una de las pocas utopias que siguen en pie y la única revolución triunfante de este siglo, revolución que si fue avanzando en las cuatro esquinas del mundo y que se efectuó sin fusiles, sin tanques, sin ejércitos y sin un solo muerto.

Florence Tomas (1999)

Dentro de lo que han significado los procesos históricos y el despertar de todos los grupos oprimidos, la mujer se plantea como uno de los poros que estallan, como uno de los puntos que ataca y cuestiona el poder social que la coacciona. Históricamente este movimiento se ha llamado feminista y ha querido significar algo más que femenino o de mujeres en general. Con esta palabra "feminista» se ha querido abarcar a la mujer, a las mujeres (en grupos o independientes) que nos agrupamos en una causa común, que cuestionando la forma social de relacionarse, cuestionamos el gesto "natural" que nos discrimina como "mujeres».

Que afirmamos una causa, no como minoría oprimida sino como más de la mitad de la población que no quiere estar más sumida. (...) La transformación

de las relaciones que nos oprimen como mujeres potenciará cualquier causa porque obraremos no como sombras o complementos sino como personas. La causa feminista las atraviesa todas. Es la herida profunda que lo recorre todo. Martha Cecilia Herrera Cortés y María Cristina Suaza Vargas, Bogotá, 1980

El feminismo está vivo donde quiera que haya una mujer feminista porque el feminismo es una forma de ver y de mirar el mundo.

Cris Suasa (2009)

Gracias, Florence, Martha Cecilia, Cris y todas las mujeres que hace treinta años, hicieron posible un Primer encuentro feminista latinoamericano y del Caribe, quienes en 1980 afirmaban con la fuerza de la historia de las mujeres. Gracias a las mujeres que desde ese otro continente con el cual nos encontramos para reconocernos como Iberoamérica con quienes interrogamos hoy, desde la posibilidad antes no existente en la historia de reconocernos como pares, las relaciones entre lo local y lo global: 
La influencia del feminismo va in crescendo en progresión geométrica. A finales del siglo XX el feminismo ha penetrado en muchos espacios de la realidad social. El feminismo del siglo XXI debe clarificar las conexiones de los ideales de los diferentes feminismos. $Y$ en ese sentido debe pensar globalmente al mismo tiempo que actuar de manera local. Pero siempre contrastando los discursos con las prácticas sociales y nunca olvidando los hechos.

Amelia Valcárcel, Andalucía, España, 2000.

Gracias a las mujeres latinoamericanas que concentran la mirada en las propuestas gestadas en este continente y nos animan a mantener vivos los necesarios nexos entre una modernidad cuyos valores aún no se han realizado y una postmodernidad que busca nuevos discursos, nuevas prácticas y nuevas rupturas que nos mantienen alertas:

De hecho, la autonomía politica de las mujeres es un rasgo distintivo del movimiento feminista. En eso, hasta los noventa, coincidian todas las formas feministas del movimiento de liberación: liberales, socialistas, radicales, de la diferencia sexual y académicas. En su búsqueda de la igualdad de derechos, las mujeres organizadas han sido ridiculizadas, menospreciadas, asesinadas, pero desde hace una década, de repente, parece que la igualdad está al alcance de sus manos.

Personajes cinematográficos de mujeres peleadoras, amazonas en la televisión, ministras de estado, presidentas de corporaciones financieras: la imagen está creada.

Pero no, la universalidad les está vedada; su diferencia sigue visualizándose como contingente, anecdótica, no constitutiva de la humanidad. (...) El feminismo hoy más que nunca vive gracias a sus diferencias internas. Es un movimiento de movimientos, algunas veces en diálogo, otras enfrentados, la mayoría de las veces desconociéndose mutuamente. (...) Estoy convencida de que la utopia, a pesar de todos los límites que pueda tener el concepto, es el espacio ético por excelencia desde donde pugnar por una política de las mujeres que informe a la macrocultura de la supremacía masculina acerca de nuestras formas de interacción. Francesca Gargallo, Bogotá, Colombia, 2004

Gracias a Paulina Triviño, a las Mujeres de Fundac y con ellas a todas las mujeres que han ido tejiendo redes que animan el encuentro entre las diversas expresiones organizativas de las mujeres de sectores populares y del amplio movimiento social de mujeres con quienes transitamos para descubrir las profundas huellas que dejan en nuestros cuerpos las historias inscritas en los cuerpos de quienes portan una, dos, tres o más diferencias que ancestralmente han sido objeto de discriminación:

La formación y capacitación que he recibido ha estado influenciada por el feminismo y orientada por la educación popular y la pedagogía de género como forma de ver y entender el mundo, y sobre todo como práctica social 
para avanzar en el ejercicio de la libertad y de la autonomía que aporta a la construcción de la democracia. (...) He ganado en capacidad de concertación, de gestión, de construcción de alianzas. La claridad y la certeza de que los derechos humanos y los derechos humanos de las mujeres se deben cumplir en todo el territorio nacional; la certeza de que las leyes y las politicas son susceptibles de cambio, y sabiendo las limitaciones y falta de voluntad politica que encontramos en las instituciones y corporaciones públicas, hoy seguimos reafirmando que con organización y con una participación consciente, decidida y propositiva lograremos lo que nos propongamos.

Paulina Triviño, Bogotá, Colombia, 2009

Gracias a todas ellas por enseñarnos el valor de conversar entre mujeres y de conversar con mujeres. Gracias por hacer posible reconocer y asumir las tensiones presentes en esa conflictiva y promisoria relación entre el feminismo y los feminismos, el movimiento social de mujeres, otros movimientos sociales, la academia, el estado y las siempre necesarias preguntas y denuncias sobre la omnipresencia del poder patriarcal que aún en extinción se resiste a desaparecer.

Gracias por hacer posible el paso de la soberanía de los pueblos a la soberanía de nuestros cuerpos.

Gracias por las posibilidades que este encuentro nos ofrece para mantener las tensiones entre disentir y consensuar, armonizar y conflictuar, incidir y decidir siempre presentes en las dinámicas cambiantes del movimiento feminista y del más amplio movimiento social de mujeres que toma la palabra para interpelar con la firmeza y la fuerza de la construcción, del valor de la sororidad como posibilidad del diálogo entre libertad, igualdad y sororidad que nos permiten y nos obligan a seguir interpelando al Estado, la Academia, la Sociedad civil, deconstruyendo y reconstruyendo las relaciones entre éstas, siempre desde lo que somos y lo que hacemos, o mejor, desde lo que vamos siendo a medida que vamos haciendo.

\section{Bibliografía}

Gama, Juanita. 2009. «Mujeres, géneros, subjetividad y democracia». Otras Palabras... 17: 17-21.

Barreto Gama, Juanita. 2007. «Mujeres, géneros y feminismos. Reflexiones para un debate». En: Luz Gabriela Arango y Yolanda Puyana (comp.). Género, mujeres y saberes. Entre el movimiento social, la academia y el Estado. Pp. 191-199. Bogotá, Universidad Nacional de Colombia, Facultad de Ciencias Humanas, Escuela de Estudios de Género. Unibiblos.

Barreto Gama, Juanita. 2006. "La diversidad: un conflicto en la construcción de la ciudadanía» En: María Teresa Cifuentes y Adrián Serna (comp.). Ciudadanía y conflicto. Memorias del Seminario Internacional. Pp. 123-138. Bogotá, Universidad Distrital Francisco José de Caldas. 
Barreto Gama, Juanita. 2005. «El pensamiento feminista y los estudios de género en los debates sobre transdisciplinariedad. En: Jaime Eduardo Jaramillo Jiménez (comp.), "Cultura, identidades y saberes fronterizos». Centro de Estudios Sociales CES, Facultad de Ciencias Humanas, Universidad Nacional de Colombia. Bogotá. "Cultura, identidades y saberes fronterizos: Memorias del Congreso Internacional Nuevos paradigmas transdisciplinarios en ciencias humanas». Pp. 275-285. Bogotá, Ed. Facultad de Ciencias Humanas, Universidad Nacional de Colombia, Colección CES.

Barry, Jane y Jelena Djordjevic. 2008. «¿Qué sentido tiene la revolución si no podemos bailar?». [html] Publicado por Urgent Action Found. Recuperado de: http://www. fondoalquimia.org/Que-sentido-tiene-la-revolucion-si.html

Bocchetti, Alessandra. 1995. Lo que quiere una mujer. Madrid, Cátedra, Universitat de Valencia, Instituto de la Mujer.

Gargallo, Francesca. 2004. Las ideas feministas latinoamericanas. Bogotá, Desde Abajo.

Grupo mujer y sociedad. 1990. Mujer, amor y violencia. Nuevas interpretaciones de antiguas realidades. Bogotá, Universidad Nacional de Colombia-Tercer Mundo Editores.

Guerra, Lucía. 1995. La mujer fragmentada. Historia de un signo. Santiago de Chile, Cuarto Propio.

Lagarde, Marcela. 2000. Claves feministas para el poderío y la autonomía de las mujeres. Sevilla, Instituto Andaluz de la Mujer.

República de Colombia. 1991. Constitución política de Colombia. Bogotá, República de Colombia.

Santos Velásquez, Luis. 2009. Masculino y femenino en la intersección entre el psicoanálisis y los estudios de género. Bogotá, Centro editorial Facultad de Ciencias Humanas, Universidad Nacional de Colombia.

Suaza, Cris. 2009. Soñé que soñaba. Bogotá, Agencia española de Cooperación Internacional para el Desarrollo (AECID).

Thomas, Florence. 1999. "Abriendo caminos a la irreverencia o el derrumbe de los imaginarios «en otras palabras» y... en forma de léxico», Otras Palabras... 6: 92-95.

Trivińo, Paulina. 2009. «Mis experiencias con el feminismo, la perspectiva de género y la democracia». Otras Palabras... 17: 130-135.

Valcárcel, Amelia, María Dolores Renau y Rosalía Romero. 2000. Los desafíos del feminismo ante el siglo XXI. Madrid, Instituto Andaluz de la Mujer.

Woolf, Virginia. 1993 [1928]. Un cuarto propio. Conferencia Girton College, Cambridge, (publicado por el Instituto Chileno Británico de Cultura Editorial Cuarto Propio, traducido por Edmundo Moure y Marisol Moreno sobre la base de una adaptación libre de la traducción de Jorge Luis Borges). Santiago de Chile. 